WHO Collaborating Centre for Metabolic Bone

Diseases, Department of Human Metabolism and Clinical Biochemistry, University of Sheffield Medical School, Sheffield S10 2RX

John A Kanis, professor

Malmo General Hospital, S-214 01 Malmo, Sweden Olof Johnell, professor of orthopaedics

Bo Gullberg, senior lecturer in medical statistics

Department of Social Medicine, Huddinge University Hospital, S-141 86 Huddinge, Sweden

Erik Allander, professor

Istanbul Universitesi, Capa Tip Fakultesi, Fiziksel Tip ve Rehabiliasyon, Istanbul, Turkey

Güzin Dilşen, professor

University of Siena, 53100 Siena, Italy

Carlo Gennari, professor

Rua Gaspar Correia 87, 4100 Porto, Portugal A A Lopes Vaz, professor

Th Garofalidis Research Centre, Accident Hospital, GR-145 61 Kifissia, Greece George P Lyritis, professor

Policlinico Umberto I, II Clinica Medica, 00161 Roma, Italy

Gianfranco Mazzuoli, professor

Unite INSERM No 18, Centre Andre Lichtwitz, 75010 Paris, France

Livia Miravet, professor

Istituto di Clinica Medica Generale e Terapia Medica, 43100 Parma, Italy

Mario Passeri, professor

Sant Francisco Javier, 60-6a, 41005 Sevilla, Spain Ramon Perez Cano, professor

Department of Internal Medicine, Fundacion Jimenez Diaz, Avda Reyes Catolicos 2, 28040 Madrid, Spain

Aurelio Rapado, professor

Service d'Endocrinologie, CHU Toulouse Purpan, 31059 Toulouse Cedex, France

Claude Ribot, professor

\title{
Evidence for efficacy of drugs affecting bone metabolism in preventing hip fracture
}

\author{
John A Kanis, Olof Johnell, Bo Gullberg, Erik Allander, Güzin Dilşen, Carlo Gennari, \\ A A Lopes Vaz, George P Lyritis, Gianfranco Mazzuoli, Livia Miravet, Mario Passeri, \\ Ramon Perez Cano, Aurelio Rapado, Claude Ribot
}

\section{Abstract}

Objective-To examine the effects of taking drugs affecting bone metabolism on the risk of hip fracture in women aged over 50 years.

Design-Retrospective, population based, casecontrol study by questionnaire.

Setting-14 centres in six countries in southern Europe.

Subjects-2086 women with hip fracture and 3532 control women matched for age.

Main outcome measures-Number of drugs affecting bone metabolism taken and length taken for.

Results-Women taking drugs affecting bone metabolism had a significantly decreased risk of hip fracture. After adjustment for differences in other risk factors, the relative risk of hip fractures was 0.55 $(95 \%$ confidence interval 0.31 to 0.85$)$ in women taking oestrogens, $0.75(0.60$ to 0.94$)$ in those taking calcium, and $0.69(0.51$ to 0.92$)$ in those taking calcitonin. The fall in risk was not significant for anabolic steroids $(0.6(0.29$ to 1.22$))$. Neither vitamin $D$ nor fluorides were associated with a significant decrease in the risk of hip fracture. The effect on hip fracture risk increased significantly with increasing duration of exposure (risk ratio $0.8(0.61$ to 1.05$)$ for less than median exposure $v 0.66(0.5$ to 0.88$)$ for greater than median exposure). Drugs were equally effective in older and younger women, with the exception of oestrogen.

Conclusions-Oestrogen, calcium, and calcitonins significantly decrease the risk of hip fracture. Short term intervention late in the natural course of osteoporosis may have significant effects on the incidence of hip fracture.

\section{Introduction}

Many drugs are capable of decreasing the rate of bone loss in osteoporosis, including gonadal steroids,' calcitonins, ${ }^{2}$ bisphosphonates, ${ }^{34}$ anabolic steroids, ${ }^{30}$ and pharmacological doses of calcium. ${ }^{7}$ The evidence that vitamin $\mathrm{D}$ and its analogues significantly modulate the rate of bone loss in osteoporosis is more controversial, and the results between centres differ ${ }^{89}$ The most noticeable effects on bone mass in patients with osteoporosis are obtained with sodium fluoride, and data indicate that skeletal mass can be restored. ${ }^{10}$ Nevertheless, with the exception of oestrogens, ${ }^{111-13}$ there is little direct evidence that these agents decrease the risk of hip fracture. Indeed, prevention of bone loss may not always be associated with a proportionate decrease in risk of fracture. ${ }^{14}{ }^{15} \mathrm{~A}$ recent well conducted prospective study showed little overall benefit from fluoride on overall risk of fracture despite substantial increases in bone mineral density. ${ }^{10}$ Such data have increased awareness of the need to study the effects of interventions on fracture in established osteoporosis.

Most prospective studies of treatment have assessed the effect on the frequency of vertebral fracture. One reason for this is that multiple vertebral fracture is more common than hip fracture, making it possible to

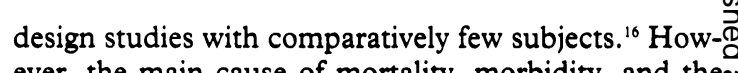
ever, the main cause of mortality, morbidity, and theg drain on economic resources arises from hip fracture in elderly patients. In addition, there is no compelling. evidence that preventing vertebral fracture will necessarily prevent hip fracture, particularly in very oldo people. Some drugs that decrease the risk of vertebralo fracture might have an adverse effect on the risk of appendicular fractures. ${ }^{410}$

For these reasons, we included questions on previous exposure to drugs affecting bone metabolismo in women with hip fracture and controls in a question- naire administered during the Mediterranean osteoporosis study (MEDOS). ${ }^{17}$

\section{Subjects and methods}

The Mediterranean osteoporosis study examined the incidence of hip fracture in men and women aged 3 50 years or over from 14 centres from six countries in southern Europe. Investigators from each centre provided prospective information on the hip fracturese which occurred over one year (1988-9) from a defined ${ }^{N}$ catchment area. Where possible, each case and two controls were interviewed by a trained observer in thes local language using a structured questionnaire. ${ }^{17} \mathrm{~A}$ component of the questionnaire related to the use of drugs affecting bone metabolism and our findings are the basis of this report.

\section{CASES AND CONTROLS}

The cases comprised women aged 50 years or overo who had had a femoral neck fracture during the study period. Cases were identified by surveillance of hospitals, private clinics, and nursing homes in the catchment area. Women had to be resident in the catchment area, irrespective of the place where then fracture occurred. Women who had had a previous hip fracture were not excluded. Women were not inter-o viewed if they refused or were unable to comply because of illness. In the second case a suitable relativecr was interviewed if possible. Cases in which no informa $\rightarrow$ tion was recorded or the woman was lost to interview were noted.

For each case two control women were identified of the same age (within three years). For this reporto controls obtained in hospital were excluded; only control women who were neighbours of cases or sampled from the population registers were included The case-control ratio varied because the number of hospital controls varied at each centre (see table I). Analysing each region's results separately did not altero the risk ratios significantly.

\section{QUESTIONNAIRE}

The questionnaire was designed in lay English to determine age, personal and family history, gonadak and reproductive status, clinical and drug history, ance environmental factors that would contribute to the risk of hip fracture. The questions were designed with the participation of all the principal investigators to 
minimise biases arising from cultural differences. Following feasibility studies ${ }^{18}$ the questionnaire was translated into the local language, back translated into English by an independent translator, and finally retranslated to the local language after correction of errors. Reliability was studied by reinterviewing 220 patients within two months. ${ }^{17}$

A total of 2086 women $(80 \%)$ with hip fracture (mean age 78 years) and 3632 controls ( $84 \%$ ) (mean age 78 years) were interviewed. Women with hip fracture were interviewed within 14 days of fracture. When possible the investigator administered the questionnaire directly to the case or control $(1325(64 \%)$ cases and 2937 (83\%) controls), sometimes with the help of a relative $(445(21 \%)$ and $322(9 \%))$; otherwise information was obtained from a close relative or other dependable source $(274(13 \%)$ and $147(4 \%))$. The source of information was undefined in $42(2 \%)$ cases and $126(4 \%)$ controls. Responses were written on coding forms suitable for automated optical reading at Stockholm. The reasons for not obtaining the interview were refusal $(835,70 \%)$, poor mental state $(250,21 \%)$, and concurrent illness or inability to contact the control $108(9 \%)$.

Women were asked whether they had ever taken any drugs specifically for osteoporotic bone disease. ${ }^{17}$ Preparations included calcium, anabolic steroids, fluoride, vitamin D compounds, calcitonins, oestrogens, and others. In addition, they were asked the age that they started treatment, the duration of treatment, and whether or not they were currently taking the preparation. Only $0.6 \%$ of controls and $0.4 \%$ of cases had taken oestrogen solely for osteoporotic bone disease so we also included women who had taken oestrogen postmenopausally for other indications.

Physical activity was assessed by inquiring about sports or physical activity undertaken outside work during the recent past, in young adulthood, and in childhood. At each period the response was scored on a three point scale (never, occasionally, more than one hour a week) and the score for each period was summed (maximum score 9). The score was combined with the responses (three point scale) concerning the physical activity excluding sports at the three ages (maximum total score $=18)$. The median score $(9)$ was used to categorise women, a high index being $\geqslant 9$ and a low index $<9$.

Calcium intake was assessed semiquantitatively from reported milk consumption in the recent past, young adulthood, and childhood. Consumption was measured on a five point scale (never, sometimes, 1-2 glasses a day, 3-4 glasses a day, $\geqslant 5$ glasses a day). A high calcium intake was defined as a total score $\geqslant 8$ (the median score). Mental score was assessed on a six point

TABLE I-Details of cases and controls by centre and exposure to drugs affecting bone metabolism

\begin{tabular}{|c|c|c|c|c|c|c|}
\hline \multirow[b]{2}{*}{ Centre } & \multicolumn{2}{|c|}{ No interviewed } & \multicolumn{2}{|c|}{$\begin{array}{l}\text { No (\%) of cases } \\
\text { taking bone drugs }\end{array}$} & \multicolumn{2}{|c|}{$\begin{array}{l}\text { No }(\%) \text { of controls } \\
\text { taking bone drugs }\end{array}$} \\
\hline & Cases & Controls & Ever & Currently & Ever & Currently \\
\hline $\begin{array}{l}\text { Portugal: } \\
\text { Porto } \\
\text { Spain: }\end{array}$ & 93 & 167 & $9 / 93(10)$ & $1 / 93(1)$ & $27 / 166(16)$ & $4 / 167(2)$ \\
\hline $\begin{array}{l}\text { Madrid } \\
\text { Seville } \\
\text { France: }\end{array}$ & $\begin{array}{r}76 \\
200\end{array}$ & $\begin{array}{l}152 \\
355\end{array}$ & $\begin{array}{c}9 / 76(12) \\
24 / 200(24)\end{array}$ & $\begin{array}{l}3 / 76(4) \\
2 / 200(1)\end{array}$ & $\begin{array}{l}11 / 152(7) \\
49 / 349(14)\end{array}$ & $\begin{array}{l}5 / 152(3) \\
7 / 355(2)\end{array}$ \\
\hline $\begin{array}{l}\text { Paris } \\
\text { Toulouse } \\
\text { Italy: }\end{array}$ & $\begin{array}{l}188 \\
338\end{array}$ & $\begin{array}{l}259 \\
723\end{array}$ & $\begin{array}{l}20 / 153(13) \\
68 / 337(20)\end{array}$ & $\begin{array}{l}15 / 188(8) \\
46 / 338(14)\end{array}$ & $\begin{array}{c}19 / 256(7) \\
176 / 721(24)\end{array}$ & $\begin{array}{c}10 / 259(4) \\
113 / 723(16)\end{array}$ \\
\hline $\begin{array}{l}\text { Parma } \\
\text { Rome } \\
\text { Siena }\end{array}$ & $\begin{array}{l}146 \\
411 \\
150\end{array}$ & $\begin{array}{l}293 \\
795 \\
171\end{array}$ & $\begin{array}{l}36 / 146(25) \\
47 / 407(12) \\
22 / 148(15)\end{array}$ & $\begin{array}{l}22 / 146(15) \\
26 / 411(6) \\
15 / 150(10)\end{array}$ & $\begin{array}{r}82 / 292(28) \\
100 / 792(13) \\
37 / 169(22)\end{array}$ & $\begin{array}{l}54 / 293(18) \\
68 / 795(9) \\
32 / 171(19)\end{array}$ \\
\hline $\begin{array}{l}\text { Greece: } \\
\text { Crete } \\
\text { Turkey: }\end{array}$ & 241 & 316 & $5 / 237(2)$ & $1 / 241(0.4)$ & $9 / 310(3)$ & $5 / 316(2)$ \\
\hline $\begin{array}{l}\text { Ankara } \\
\text { Istanbul } \\
\text { Rural areas }\end{array}$ & $\begin{array}{r}58 \\
150 \\
35\end{array}$ & $\begin{array}{r}61 \\
204 \\
36\end{array}$ & $\begin{array}{c}6 / 57(11) \\
23 / 148(16) \\
5 / 32(16)\end{array}$ & $\begin{array}{l}2 / 58(3) \\
14 / 150(9) \\
0\end{array}$ & $\begin{array}{c}8 / 61(13) \\
43 / 201(21) \\
1 / 35(3)\end{array}$ & $\begin{array}{l}2 / 61(3) \\
20 / 204(10) \\
0\end{array}$ \\
\hline All regions & 2086 & 3532 & $274 / 2034(14)$ & $147 / 2086(7)$ & $562 / 3504(16)$ & $320 / 3532(9)$ \\
\hline
\end{tabular}

BMJ VOLUME $305 \quad 7$ NOVEMBER 1992 scale $(0-5)$ by the ability to answer correctly a series of five questions. ${ }^{17} \mathrm{~A}$ high score denoted poor performance. Women were also asked about previous fractures of the forearm, hand, clavicle, ankle, humerus including elbow, tibia, femur, pelvis, hip, and vertebrae. A history of osteoporotic fracture was recorded if they had had one or more fracture associated with low energy trauma.

Information on the age of starting treatment was available for $1794(86 \%)$ cases and $3523(97 \%)$ controls and information on duration of treatment for 1579 $(88 \%)$ and $3276(93 \%)$ respectively. A smaller proportion of elderly patients gave this information than that of women below the median age $(161 / 230(70 \%)<80$ years; $189 / 231(82 \%) \geqslant 80)$.

Body mass index was calculated as weight $(\mathrm{kg})$ divided by height squared $\left(\mathrm{m}^{2}\right)$.

\section{STATISTICAL METHODS}

Adjustment to relative risk was carried out by using logistic regression models. The multivariate analysis used unconditional logistic regression. Continuous factors were categorised. To adjust for centre effects and test for interaction (heterogeneity) between centres, this factor was modelled as a categorical variable. ${ }^{19}$ Adjustment for centre included adjustment for the variable case-control ratio. Mean values were tested by the $t$ test and proportions with the $\chi^{2}$ test. All tests were two sided. Significance was assigned with a $p$ value below 0.05

\section{Results}

The proportion of women who had taken drugs affecting bone metabolism varied widely among centres (table I). The highest use occurred in Parma, Toulouse, and Siena and the lowest in Crete. Seven per cent of women with hip fracture were taking these drugs at the time of fracture, but this ranged from $0.4 \%$ (Crete) to $10 \%$ or more (Siena, Parma, Toulouse).

The pattern of drug use also varied among countries (table II). This partly reflected the pattern of licence approvals. For example, fluoride was taken almost exclusively in France but could be prescribed for osteoporosis in only France and Portugal. However, even in those drugs available in all countries (calcium, anaboli steroids, and calcitonins), use varied-for example proportions taking calcitonin differed more than eight fold. Oestrogens were most often taken in Portugal. The most commonly used drug was calcium except for Italy, where calcitonin usage was high. Overall, the most widely used preparation was calcium, followed by calcitonins, vitamin D, and oestrogens (table III). Th same pattern of exposure was noted for current drug use (data not shown). Most of the patients who had taken drugs were taking one drug at the time of interview (507/938 54\%; designating fluoride with calcium or vitamin $\mathrm{D}$, or both, as a single drug), bu taking more than one drug was common. Calcium was commonly taken with fluoride, calcitonin, or vitamin D. Excluding calcium, only 93 women took two drugs concurrently. Excluding calcium, 15 patients wer taking three or more regimens concurrently, two of whom had taken all possible preparations.

Women who had taken drugs affecting bone metabolism had a significantly reduced risk of hip fracture compared with those who had taken none (table IV). The protective effect was observed at all ages but was greatest in those below the median age (table V). Significant differences were found between women who had taken drugs affecting bone metabolism and those who had not (table VI). Women taking these drugs had a better mental score, a lowe body mass index, and a higher frequency of previous fracture. In addition, women taking these drugs more 


\begin{tabular}{|c|c|c|c|c|c|c|c|c|c|c|c|c|c|c|c|c|}
\hline \multirow[b]{2}{*}{ Country } & \multicolumn{2}{|c|}{ Calcium } & \multicolumn{2}{|c|}{ Anabolic steroids } & \multicolumn{2}{|c|}{ Fluoride } & \multicolumn{2}{|c|}{ Vitamin D compounds } & \multicolumn{2}{|c|}{ Calcitonin } & \multicolumn{2}{|c|}{ Oestrogens } & \multicolumn{2}{|c|}{ Others } & \multicolumn{2}{|c|}{ Any of these } \\
\hline & Controls & Cases & Controls & Cases & Controls & Cases & Controls & Cases & Controls & Cases & Controls & Cases & Controls & Cases & Controls & Cases \\
\hline Portugal & $9 \cdot 6(16)$ & $7 \cdot 5(7)$ & & & & & $0.6(1)$ & 0 & $3 \cdot 0(5)$ & $1 \cdot 1(1)$ & $9 \cdot 0(15)$ & $3 \cdot 2(3)$ & 0 & 0 & $16 \cdot 3(27)$ & $9 \cdot 7(9)$ \\
\hline Spain & $9.3(47)$ & $9 \cdot 4(26)$ & $0.4(2)$ & & & & $0.2(1)$ & $0 \cdot 4(1)$ & $3.0(15)$ & $1.8(5)$ & $2 \cdot 2$ (11) & $2.5(7)$ & $0.4(2)$ & 0 & $12.0(60)$ & $12.0(33)$ \\
\hline France & $14 \cdot 6(143)$ & $12 \cdot 6(66)$ & $0.4(4)$ & $0.4(2)$ & $3 \cdot 4(33)$ & $5 \cdot 7(30)$ & $10 \cdot 9(107)$ & $8.8(46)$ & $2 \cdot 0(20)$ & $2 \cdot 7(20)$ & $4 \cdot 2(41)$ & $2 \cdot 3(11)$ & $0.7(7)$ & $1 \cdot 1(6)$ & $20 \cdot 0(195)$ & $17.9(88)$ \\
\hline Italy & 10.7 (135) & $8.5(60)$ & $2 \cdot 3(29)$ & $0.4(3)$ & & & $2 \cdot 1(27)$ & $2 \cdot 3(16)$ & $13.7(173)$ & $10.6(173)$ & $2.6(33)$ & $1.4(10)$ & $0.2(3)$ & $0.1(1)$ & $17.5(219)$ & $14.9(105)$ \\
\hline Greece & $2 \cdot 2(7)$ & $0.4(1)$ & & $1 \cdot 2(3)$ & & & $0.3(1)$ & $0.8(2)$ & $1.6(5)$ & $0.4(5)$ & $0.3(1)$ & 0 & 0 & 0 & $2.9(9)$ & $2 \cdot 1(5)$ \\
\hline Turkey & $12 \cdot 0(36)$ & $11.5(28)$ & $2 \cdot 3(7)$ & $3.7(9)$ & $0 \cdot 1(3)$ & $2.5(6)$ & $4 \cdot 0(12)$ & $7 \cdot 0(17)$ & $2.7(8)$ & $2.5(8)$ & $6 \cdot 7(20)$ & $3 \cdot 3(8)$ & $1 \cdot 3(4)$ & $2 \cdot 1(5)$ & $17 \cdot 5(52)$ & $14 \cdot 0(34)$ \\
\hline All countries & $10.9(384)$ & $9 \cdot 0(188)$ & $1 \cdot 2(42)$ & $0.8(17)$ & $1 \cdot 0(36)$ & $1 \cdot 7(36)$ & $4 \cdot 2(149)$ & $3.9(82)$ & $6 \cdot 4(226)$ & $4 \cdot 9(226)$ & $3.5(121)^{\star}$ & $1.9(39)^{\star}$ & $0.5(16)$ & $0.6(12)$ & $16 \cdot 0(562)$ & $13.4(274)$ \\
\hline
\end{tabular}

TABLE III-Numbers (percentages) of control women taking or having, taken drugs affecting bone metabolism, age at starting treatment, and duration of use

\begin{tabular}{lccc}
\hline Drug & No (\%) of users & $\begin{array}{c}\text { Median (interquartile range) } \\
\text { age at starting treatment } \\
\text { (years) }\end{array}$ & $\begin{array}{c}\text { Median (interquartile range) } \\
\text { duration of treatment } \\
\text { (years) }\end{array}$ \\
\hline Calcium & $384(10 \cdot 9)$ & $72(62-78)$ & $3(1 \cdot 25-5)$ \\
Calcitonin & $226(6 \cdot 4)$ & $72(67-78)$ & $2(1-4)$ \\
Vitamin D and related compounds & $149(4 \cdot 2)$ & $73(61-80)^{\circ}$ & $4(2-8)$ \\
Anabolic steroid & $42(1 \cdot 2)$ & $70(68-74)$ & $2(1-2)$ \\
Fluorides & $36(1 \cdot 0)$ & $74(67-80)$ & $2(2-4 \cdot 5)$ \\
Oestrogens & $121(0 \cdot 6)$ & $48(40-55)$ & $5(2-10)$ \\
Others & $16(0 \cdot 5)$ & $72(60-81)$ & $1(1-5 \cdot 5)$ \\
\hline
\end{tabular}

TABLE IV-Relative risk of hip fracture according to exposure to drugs affecting bone metabolism

\begin{tabular}{|c|c|c|c|c|}
\hline \multirow[b]{2}{*}{ Drug } & \multicolumn{2}{|l|}{ Unadjusted } & \multicolumn{2}{|l|}{ Adjusted ${ }^{\star}$} \\
\hline & $\begin{array}{c}\text { Relative risk } \\
\text { (95\% confidence interval) }\end{array}$ & $\mathrm{p}$ Value & $\begin{array}{c}\text { Relative risk } \\
(95 \% \text { confidence interval) }\end{array}$ & $\mathrm{p}$ Value \\
\hline None & $1 \cdot 0$ & & $1 \cdot 0$ & \\
\hline Calcium preparations & $0.86(0.71$ to 1.03$)$ & & $0.75(0.60$ to 0.94$)$ & 0.01 \\
\hline Anabolic steroids & $0.65(0.37$ to 1.16$)$ & & $0.60(0.29$ to 1.22$)$ & \\
\hline Fluoride & $1.86(1.16$ to 3.00$)$ & 0.01 & $1.31(0.75$ to 2.29$)$ & \\
\hline Vitamin D compounds & $1.01(0.76$ to 1.34$)$ & & $0.83(0.60$ to 1.15$)$ & \\
\hline Calcitonins & $0.76(0.59$ to 0.97$)$ & 0.03 & $0.69(0.51$ to 0.92$)$ & 0.015 \\
\hline Oestrogens & $0.45(0.30$ to 0.67$)$ & 0.0001 & $0.55(0.36$ to 0.85$)$ & 0.01 \\
\hline Any of the above & $0.84(0.72$ to 0.99$)$ & 0.035 & $0.78(0.65$ to 0.95$)$ & 0.01 \\
\hline
\end{tabular}

*Adjusted for centre, age, body mass index, and previous fragility fractures.

commonly had a lower index of physical activity and more had had a hysterectomy and oophorectomy. Adjustment for age, body mass index, and previous fractures reduced the relative risk still further (table IV). Women with hip fracture had a poorer mental score than controls and in both groups mental score was poorer in those who had never taken drugs affecting bone metabolism (table VI). Exclusion of those with probable or definite dementia, adjustment for mental score, or exclusion of those without a perfect mental score did not affect our results. The effects of drug treament were consistent between centres. A longer duration of treatment was associated with the lower risk of hip fracture (table VII).

The greatest effect on hip fracture risk was seen with oestrogen treatment. Only a few patients were taking oestrogen for osteoporosis alone, and thus the difference in hip fracture risk was not significant in this group alone. When cases and controls who had taken oestrogen for other indications were included, a significant protective effect was observed (table IV). Women who had taken oestrogen for longer had the lower risk of hip fracture (table VII) both in women who had taken it perimenopausally (relative risk $0.29 ; p<0.05$ ) and in those who had taken it for osteoporosis $(0.28$; NS). Women who took oestrogen differed significantly from those who did not. They had a higher body mass index, were younger, had a better mental score, and were significantly more likely to take calcitonin. Adjustment for these factors did not alter the relative risk and the relative risk adjusted for taking calcitonin was 0.57 (95\% confidence interval 0.37 to 0.88 ; $\mathrm{p}=0.011)$. The effect of oestrogens was greatest in women under the age of 80 years (table $\mathrm{V}$ ).

Women taking calcitonin had a significantly lower risk of hip fracture than those who had not (table IV).
Such women had a significantly higher frequency ow. fractures, were younger, had a better mental score, an higher index of physical activity, but adjustment fo $\$$ these factors had no effect on the apparent riske Women taking calcitonin were also more likely to have. taken oestrogen, but the protective effect of calcitonin persisted after adjustment for taking oestrogen $\left(0 \cdot 7 \overrightarrow{\varpi_{\nu}}\right.$ $(0.52$ to 0.95$) ; p=0.023)$. Similarly, the effect o\$ calcitonin on risk of hip fracture was apparent afteg adjusting for taking calcium $(0.77(0.56$ to 1.08$)$ i. $\mathrm{p}=0.13$ ) but this was not significant. The relative contribution of calcium to the effects of calcitonin wais independent by multivariate analysis (table VIII) suggesting that a protective effect of calcitonin was. unlikely to be solely due to concurrent treatment witht calcium.

Fluoride was associated with a higher risk of hip fracture (unadjusted relative risk $=1 \cdot 86$ ). After adjust $-N$ ment for age, residence, body mass index, an $\bar{b}$ previous fracture the relative risk decreased $\left(1 \cdot 31_{\Phi}\right.$ NS). Adjustment for concurrent calcium treatmen increased the relative risk, but this was still no巴 significant. Fluoride was mainly prescribed in France but using data from France alone did not alter the relative risk.

Calcium preparations were associated with a signifio cant decrease in the risk of hip fracture, even afte adjustment for age, residence, body mass index and previous fracture. The women taking calciumo however, were more likely to have taken other druge affecting bone metabolism, particularly oestrogens and calcitonin. An effect of calcium persisted after adjust 3 ment for taking oestrogen or calcitonin, or both, bus this was not significant (relative risk $=0.82(0.64$ te. $1.05) ; p=0 \cdot 12)$. A longer duration of treatment wit calcium was associated with a lower relative ris (table VII).

Neither vitamin D nor the anabolic steroids decreased the risk of hip fracture significantly. In the case of anabolic steroids the relative risk was reduce (relative risk 0.6 ; table IV) but the number of cases was small. The effect seemed to be greater in the younger women whereas the effect of vitamin D was greater if elderly women (table V).

\section{Discussion}

The socioeconomic importance of hip fracture greater than that of other types of osteoporotic fracture but with the exception of oestrogens convincing infor mation on the use of other drugs affecting bone metabolism to prevent hip fracture is scanty. Oufor study confirms previous observations that oestrogens confer significant protection against hip fracture. ${ }^{11}$ The magnitude of effect was similar to that reported i other studies and persisted when we controlled fog other differences between women taking oestrogen and those who did not. Women taking oestrogen were heavier, had a better mental score, and were more likely to take other drugs for osteoporosis, all of whic could protect against hip fracture. But the protective effect of oestrogens persisted after accounting for these factors. On the other hand, women taking oestrogen 
also had earlier menopause and were more likely to smoke (data not shown), both of which may increase the risk of hip fracture. The significance of our findings was not altered by appropriate adjustments. The protective effect seemed greater in the younger women, as has previously been reported. ${ }^{120}$ This should not necessarily be interpreted as meaning that the effect of oestrogen wears off with time. A decrease in the relative risk is to be expected in elderly people because of the increased death rate in osteoporotic women..$^{21}$ In addition, those with the longer duration of oestrogen treatment had the lower risk of hip fracture, irrespective of whether the drug was used at the menopause or later for osteoporosis. The number of women taking oestrogens (and calcitonin and calcium) means that our findings were unlikely to have occurred by chance (power $>80 \%$ ).

Our results also suggest that other drugs may reduce the risk of hip fracture. Women taking these drugs were generally much older at the time of starting treatment (median age 70 years; table III) than those taking oestrogens (48 years). The median age was 5-6 years less than the mean age at interview. If the association we found was causal this would suggest that taking these drugs, even relatively late in the course of osteoporotic bone loss, has important dividends in terms of reducing the risk of hip fracture.

\section{EFFECTIVENESS OF DRUGS}

With the exception of fluoride, all the drugs that we examined seemed to decrease the risk of hip fracture. With the exception of oestrogens, the drugs were equally effective in older and younger women and the effects were greater with the longer duration of treatment. These data agree with the known effects of these drugs to decrease the rate of bone loss. Although the effects of calcium nutrition on hip fracture risk are controversial, ${ }^{22} 23$ pharmacological doses of calcium have been shown to delay the rate of bone loss. The effect seems to be less complete than that with anabolic steroids, calcitonins, and oestrogen. The more modest decrease in relative risk with calcium agrees with these observations. Of particular interest is the significant effect of calcitonin, and to our knowledge this is the first report suggesting that calcitonin (with calcium) significantly decreases the risk of hip fracture.

The effects of fluorides on vertebral crush fracture

TABLE $\mathrm{V}-$ Relative risk of hip fracture according to age *

\begin{tabular}{|c|c|c|c|c|}
\hline \multirow[b]{2}{*}{ Drug } & \multicolumn{2}{|l|}{ Age $<80$ years } & \multicolumn{2}{|l|}{ Age $\geqslant 80$ years } \\
\hline & $\begin{array}{c}\text { Relative risk } \\
(95 \% \text { confidence interval) }\end{array}$ & $\mathrm{p}$ Value & $\begin{array}{c}\text { Relative risk } \\
(95 \% \text { confidence interval) }\end{array}$ & $\mathrm{p}$ Value \\
\hline Calcium preparations & $0.85(0.64$ to 1.13$)$ & & $0.61(0.43$ to 0.87$)$ & 0.006 \\
\hline Anabolic steroids & $0.43(0.17$ to 1.09$)$ & 0.075 & $1.01(0.29$ to 3.45$)$ & \\
\hline Fluoride & $0.91(0.41$ to 2.04$)$ & & $1.72(0.78$ to 3.79$)$ & \\
\hline Vitamin D compounds & $1.04(0.65$ to 1.67$)$ & & $0.68(0.44$ to 1.07$)$ & 0.093 \\
\hline Calcitonins & $0.67(0.46$ to 0.96$)$ & 0.03 & $0.69(0.42$ to 1.15$)$ & \\
\hline Oestrogens & $0.51(0.31$ to 0.84$)$ & 0.009 & $0.70(0.29$ to 1.66$)$ & \\
\hline Any of the above & $0.82(0.64$ to 1.05$)$ & & $0.73(0.54$ to 0.98$)$ & 0.034 \\
\hline
\end{tabular}

^The odds ratios are adjusted for age, previous fractures, and body mass index. There were no significant differences The odds ratios are adjusted for
in odds ratio between age groups.
TABLE VII-Relative risk ( $95 \%$ confidence interval) of hip fracture adjusted for age, body mass index, previous fractures, and centr according to length of treatment with drugs affecting bone metabolism

\begin{tabular}{|c|c|c|c|}
\hline \multirow[b]{2}{*}{$\begin{array}{l}\text { Drug (median } \\
\text { duration of } \\
\text { treatment } \\
\text { in years) }\end{array}$} & \multicolumn{3}{|c|}{ Length of treatment } \\
\hline & Never & $\begin{array}{l}\text { Less than median } \\
\text { duration }\end{array}$ & $\begin{array}{l}\text { Greater than or } \\
\text { equal to median } \\
\text { duration }\end{array}$ \\
\hline Calcium (3) & $1 \cdot 0$ & $0.83(0.59$ to 1.15$)$ & $0.59(0.43 \text { to } 8.80)^{\star}$ \\
\hline Oestrogen (5) & $1 \cdot 0$ & $0.86(0.51$ to 1.46$)$ & $0.29(0.13$ to 0.61$)$ \\
\hline Calcitonin (2) & $1 \cdot 0$ & $0.63(0.41 \text { to } 0.96)^{\star}$ & $0.71(0.45 \text { to } 1.12)^{\star}$ \\
\hline Any (?) & $1 \cdot 0$ & $0.80(0.61$ to 1.05$)$ & $0.66(0.50 \text { to } 0.88)^{\star}$ \\
\hline
\end{tabular}

TABLE VIII-Multivariate analysis of the effects of calcitonin and calcium on the risk of hip fracture

\begin{tabular}{lcr}
\hline Treatment & $\begin{array}{c}\text { Relative risk } \\
(95 \% \text { confidence interval) }\end{array}$ & p Value \\
\hline None & 1.00 & \\
Calcium & $0.82(0.63$ to 1.07$)$ & 0.149 \\
Calcitonin & $0.78(0.48$ to 1.27$)$ & 0.318 \\
Calcium plus calcitonin & $0.63(0.44$ to 0.90$)$ & 0.012 \\
\hline The product of the odds ratio for taking either drug alone $(0.64)$ is similar to \\
that for the combination suggesting an independent effect of each drug.
\end{tabular}
that for the combination suggesting an independent effect of each drug.

are controversial, as are their effects on hip fracture. Fluoride has been suggested to increase the risk of hip fracture despite the preservation of femoral bone mass. ${ }^{10}$ In our study fluoride seemed to be associated with a significantly increased risk of hip fracture (unadjusted relative risk 1.86 ; table IV). As in the case of the other drugs used there were significant differences between women taking fluoride and those not taking it, which may have confounded the association. Indeed, when account was taken for age, previous fractures, and body mass index, the relative risk decreased $(1 \cdot 31 ; 95 \%$ confidence interval 0.75 to $2 \cdot 29)$ and was no longer significant. Fluoride was taken by relatively few patients, however, and the conclusion that fluoride does not increase the risk of hip fracture significantly would require a larger sample size to have sufficient power.

\section{SOURCES OF ERROR}

Apart from those whom we could not interview, a major potential source of bias was that we included interviews in women who had senile dementia (18\% of cases and $6 \%$ controls). Recall of drug use was probably incomplete and unreliable in such patients. Although patterns of drug use may be different in people with dementia, this is unlikely to create a false association between drug use and the risk of fracture. Our results did not differ when patients with dementia were excluded, and adjustment for mental score had no significant effect on our findings. Several confounding factors were identified, particularly body mass index and age. After adjustment for these, the greatest residual factor was a history of fragility fractures. Thus, women taking drugs affecting drug metabolism were more likely to have fractures for this reason. When account was taken of previous fracture, the effects of treatments on risk of hip fracture were

TABLE VI-Characteristics of women who had never and ever taken drugs affecting bone metabolism. Values are numbers (percentages) unless stated otherwise

\begin{tabular}{|c|c|c|c|c|c|c|c|c|c|c|c|c|c|c|}
\hline & \multicolumn{2}{|c|}{ Calcium preparations } & \multicolumn{2}{|c|}{ Anabolic steroids } & \multicolumn{2}{|c|}{ Fluoride } & \multicolumn{2}{|c|}{ Vitamin D compounds } & \multicolumn{2}{|c|}{ Calcitonins } & \multicolumn{2}{|c|}{ Oestrogens } & \multicolumn{2}{|c|}{ Any } \\
\hline & Never & Ever & Never & Ever & Never & Ever & Never & Ever & Never & Ever & Never & Ever & Never & Ever \\
\hline Age (years) & 78 & $77^{\star}$ & 78 & $75^{*}$ & 78 & 77 & 78 & $80^{*}$ & 78 & $76^{\star}$ & 78 & $73^{*}$ & 78 & 77 \\
\hline Body mass index $\left(\mathrm{kg} / \mathrm{m}^{\prime}\right)$ & $24 \cdot 8$ & $23 \cdot 7^{\star}$ & $24 \cdot 7$ & $24 \cdot 1$ & $24 \cdot 7$ & $22 \cdot 8^{*}$ & $24 \cdot 8^{\star}$ & $22 \cdot 2^{\star}$ & $24 \cdot 7$ & $24 \cdot 7$ & $24 \cdot 7$ & $25 \cdot 6^{*}$ & $24 \cdot 8$ & $24 \cdot 2^{\star}$ \\
\hline $\begin{array}{l}\text { Previous fractures } \\
\text { Hysterectomy with }\end{array}$ & $595 / 5046(12)$ & $164 / 572(29)^{*}$ & $739 / 5559(13)$ & $20 / 59(34)^{\star}$ & $724 / 5546(13)$ & $35 / 72(49)^{\star}$ & $692 / 5387(13)$ & $67 / 231(29)^{*}$ & $666 / 5290(13)$ & $93 / 328(28)^{*}$ & $723 / 5378(13)$ & $24 / 160(15)$ & $542 / 4702(12)$ & $205 / 836(25)^{\star}$ \\
\hline $\begin{array}{l}\text { oophorectomy } \\
\text { High calcium }\end{array}$ & $343 / 4124(8)$ & $61 / 452(14)^{*}$ & $396 / 4528(9)$ & $8 / 48(17)$ & $400 / 404(9)$ & $4 / 42(10)$ & $379 / 4392(9)$ & $25 / 181(14)^{*}$ & * $379 / 4325(9)$ & $25 / 251(10)$ & $362 / 4426(8)$ & $38 / 118(32)^{*}$ & $298 / 3899(8)$ & $102 / 645(16)^{*}$ \\
\hline consumption† & $2162 / 487(44)$ & $274 / 559(49)^{*}$ & $2412 / 5381(45)$ & $24 / 57(42)$ & $2410 / 5373(45)$ & $26 / 61(38)$ & $2328 / 5218(45)$ & $108 / 270$ & $2277 / 5116(45)$ & $159 / 322(49)$ & $2355 / 5244(45)$ & $61 / 152(40)$ & $2026 / 4573(44)$ & $390 / 823(47)$ \\
\hline $\begin{array}{l}\text { Other bone drugs } \\
\text { Other bone agents }\end{array}$ & $271 / 4973(5)$ & $397 / 565(70)^{*}$ & $777 / 5479(14)$ & $52 / 59(88)^{*}$ & $766 / 568(14)$ & $69 / 70(99)^{*}$ & $611 / 5313(11)$ & $204 / 225(91)^{*}$ & $512 / 5212(10)$ & $238 / 326(73)^{*}$ & $679 / 5378(13)$ & $45 / 160(28)$ & & \\
\hline $\begin{array}{l}\text { (excluding calcium) } \\
\text { (antoret }\end{array}$ & $271 / 4973(5)$ & $\begin{array}{c}397 / 565(70)^{*} \\
0.5\end{array}$ & $\begin{array}{c}609 / 5479(11) \\
0.6\end{array}$ & $\begin{array}{l}45 / 59(76)^{*} \\
45 / 59(0 \cdot 3)^{*}\end{array}$ & $\begin{array}{c}598 / 5468(11) \\
0.6\end{array}$ & $\begin{array}{l}50 / 70(72)^{*} \\
0.3^{*}\end{array}$ & $\begin{array}{c}443 / 5313(8) \\
0.5\end{array}$ & $\begin{array}{l}105 / 225(47)^{*} \\
0.8^{*}\end{array}$ & $\begin{array}{c}342 / 5212(7) \\
0.6\end{array}$ & $\begin{array}{l}105 / 326(32)^{*} \\
0.4^{*}\end{array}$ & $\begin{array}{c}505 / 5378(9) \\
0.5\end{array}$ & $43 / 160(27)^{*}$ & 0.55 & $0.46^{*}$ \\
\hline
\end{tabular}
Mental scoreł $\begin{array}{cccccc}271 / 4973(5) & 397 / 565(70)^{*} & 609 / 5479(11) & 45 / 59(76)^{*} & 598 / 5468(11) & 50 / 70(72) \\ 0.6 & 0.5 & 0.6 & 45 / 59(0.3)^{*} & 0.6 & 0.3^{*}\end{array}$ $\begin{array}{llllll}0.5 & 0.8^{*} & 0.6 & 0.4^{*} & 0.5 & 0.37 / 60(27)\end{array}$ ${ }^{*} \mathrm{p}>0.05$ Between never and ever users $\left(t\right.$ test or $\chi^{2}$ test $)$. 
greater. Recent studies have indicated that mortality is increased in women with lower bone mineral density. ${ }^{21}$ Thus, in our series of elderly women there may have been fewer women with low bone density because of early deaths. If so, this would lead to an underestimate of the effects of the drugs.

\section{VARIATIONS IN USE}

The use of drugs affecting bone metabolism differed among countries, ranging from $3 \%$ to $20 \%$ in the communities studied (table II). The type of drug also varied, even after taking account of restrictions imposed by registration authorities. The greatest variability in use between countries was seen for calcitonin (8.5-fold difference) and oestrogens (30-fold). Even among women taking drugs for which we had sufficient power to detect a decreased risk of hip fracture, the proportion taking the drugs was relatively low (table II). The adjusted proportional fractures that were prevented (analogous to attributable risk) by taking these agents was therefore also low $(2 \cdot 2 \%$ for calcitonin; 1.5 for oestrogens and $2.9 \%$ for calcium). Thus, if the associations we describe are causal then these drugs prevented $3.6 \%$ of hip fractures. It is ironic that the number of women taking each drug was inversely related to apparent efficacy, so changing the treatment of those most at risk to more effective regimens would have saved twice as many fractures.

We conclude that drugs affecting bone metabolism including oestrogens, calcium, and calcitonins significantly reduce the risk of hip fractures. This supports their use in the prevention of hip fractures; for calcium and the calcitonins, treatment relatively late in the natural course of postmenopausal bone loss may be worth while.

We thank the World Health Organisation and the European Foundation for Osteoporosis and Bone Disease for sponsoring these studies and Sandoz, Basel, for financial support. We thank Mr D Keen, Dr A Gonzalez, and Dr J-C Becker for their help and other members of the project management group: J Dequeker, D Loew, N Khaltaev, and M Pluss.

\section{How useful do parents find home peak flow monitoring for children with asthma?}

\section{B W Lloyd, M H Ali}

\section{North Middlesex Hospital NHS Trust, London N18 1QX \\ B W Lloyd, consultant paediatrician}

\section{Royal Free Hospital, London NW3 2QG $\mathrm{MH} \mathrm{Ali}$, lecturer in community child health}

Correspondence to: Dr Lloyd.

BMF 1992;305:1128-9
Home peak flow monitoring is increasingly seen as standard practice in the management of adults and children with asthma. ${ }^{1-3}$ We prescribe a peak flow meter to all children over 5 years old who attend our clinic with asthma. We ask parents to ascertain their child's best peak flow reading and we then assign a "danger" peak flow level (usually $60 \%$ of the child's best).

We decided to study how useful parents find home peak flow monitoring and in what ways they use their peak flow meters. We also assessed parents' understanding of home peak flow monitoring by testing their recall of their child's best and danger peak flow levels.

\section{Methods and results}

The parents of 50 consecutive asthmatic children over 5 years old attending our clinic were included in the study provided that they could write English and provided that they had attended the clinic at least once before since receiving a peak flow meter. They were given the following questionnaire to complete before
1 Ettinger B, Genant HK, Cann CE. Long-term estrogen replacement therapy prevents bone loss and fractures. Ann Intern Med 1985;102:319-24.

2 MacIntyre I, Stevenson JC, Whitehead MI, Wimalawansa SJ, Banks LM Healey MJR. Calcitonin for prevention of postmenopausal bone loss. Lancet 1988;1:900-2.

3 Storm T, Thamsborg G, Steiniche T, Genant HK, Sorensen OH. Effect of intermittent cyclical etidronate therapy on bone mass and fracture rate in postmenopausal osteoporosis. N Engl f Med 1990;322:1265-71.

4 Watts NB, Harris ST, Genant HK, Wasnich RD, Miller PD, Jackson RD, et al. Intermittent cyclical etidronate treatment of postmenopausal osteo et al. Intermittent cyclical etidronate

5 Geusens P, Dequeker J, Verstraeten A, Nijs J. Bone response to termination nandrolone decanoate, $1-\alpha$ vitamin $\mathrm{D}_{3}$ and calcium infusion treatment in
osteoporosis. In: Christiansen $\mathrm{C}$, Johansen JS, Riis BJ, eds. Osteoporos osteoporosis. In: Christiansen C, Johansen JS, Riis BJ, eds. Osteoporosif Copenhagen: Osteopress ApS, 1977:966-8

6 Chesnut CH, Ivey $\mathrm{L}$, Gruber HE, Matthews M, Nelp WB, Sisom Stanozolol in post-menopausal osteoporosis: therapeutic efficacy anf possible mechanism of action. Metabolism 1983;32:571-80.

7 Kanis JA, Passmore R. Calcium supplementation of the diet. BMF 1989;29 137-40, 205-8

8 Dawson-Hughes B, Dallal GE, Krall EA, Harris S, Sokoll LJ, Falconer $\mathbb{\mathscr { Q }}$ Effect of vitamin D supplementation on winter-time and overall bone loss $\%$ healthy postmenopausal women. Ann Intern Med 1991;115:505-12.

9 Ott SM, Chesnut CH. Calcitriol treatment is not effective in postmenopaus osteoporosis. Ann Intern Med 1989;110:267-74.

10 Riggs BL, Hodgson SF, O'Fallon WM, Chao EYS, Wahner HW, Muhs IML et al. Effect of fluoride treatment on the fracture rate in postmenopaus women with osteoporosis. N Engl I Med 1990;322:802-9.

11 Hutchison TA, Polansky SM, Feinstein AR. Postmenopausal oestroger protect against fractures of hip and distal radius: a case-control study. Lan 1979;ii:705-9.

12 Naessen T, Persson I, Adami H-O, Bergstrom R, Berqvist L. Hormore replacement therapy and the risk for first hip fracture. Ann Intern Med 1990;113:95-103

13 Weiss NS, Carol PH, Ure L, Ballard JH, Williams AR, Daling JR. Decreasడ్ risk of fractures of the hip and lower forearm with postmenopausal use DP estrogen. N Engl f Med 1980;303:1195-8.

14 Kanis JA, Geusens P, Christiansen C. Guidelines for clinical trials osteoporosis. Osteoporosis International 1991;1:182-8.

15 Consensus Development Conference. Prophylaxis and treatment of oste을 porosis. Osteoporosis International 1991;1:114-7.

16 Kanis JA. Treatment of osteoporotic fracture. Lancet 1984; $27-33$.

17 Dequeker J, Ranstam J, Valsson J, Sigurgevisson B, Allender E MEDOT Study Group. The Mediterranean osteoporosis (MEDOS) study questio naire. Clin Rheumatol 1991;10:54-72.

18 Dequeker J, Tobing L, Rutten V, Geusens P, MEDOS Study Group. Relative risk factors for osteoporotic fracture: a pilot study of the MEDQ questionnaire. Clin Rheumatol 1991;10:49-53.

19 Hosmer D, Lemeshow S. Applied logistic regression. New York: John Wiley and

Sons, 1989 .
20 Law MR, Wald NJ, Meade TW. Strategies for the prevention of hip fracturs BMf 1991;303:453-9.

21 Browner WS, Seeley DG, Vogt TM, Cummings SR. Non-trauma mortality $\mathbb{D}$ elderly women with low bone mineral density. Lancet 1991;338:355-8.

22 Cooper C, Barker DJP, Wickham C. Physical activity, muscle strength, an calcium intake in fracture of the proximal femur in Britain. BMF 1988;29 1443-6.

23 Kanis JA. Calcium requirements for optimal skeletal health in wome Calcif Tissue Int 1991;49(suppl):S33-41.

(Accepted 1 September 1992)

entering the consulting room: (1) What is the best peak flow level that your child has ever blown? (2) What your child's danger peak flow? (3) How useful do you find your peak flow meter (very useful, useful, not vero useful, useless)? (4) Now please write as much as yout like about how the peak flow meter helps you look aftef your child's asthma.

Some parents were carrying a National Asthmo Campaign card (with details of their child's best and danger peak flow readings). We emphasised the importance of not consulting the card while theog completed the questionnaire. In a few cases we confiscated the card temporarily. A nurse was usuali present while they completed the questionnaire.

Forty two of the 50 parents remembered their child danger peak flow to within $10 \%$ of the correct value The same number remembered their child's best pea flow level to within $10 \%$. Thirty five parents rated the peak flow meter as very useful. Fourteen rated it an useful. One parent rated the peak flow meter as uselese Almost all the uses for home peak flow monitoring tha were volunteered in writing by parents fell into one $\mathbb{A}$ three categories.

Forty four of the 50 parents cited the usefulness of home peak flow monitoring for judging the severity an episode of asthma. Twenty three parents stated the it helped them judge their child's response to bronch dilators. Ten parents wrote that it helped them detect asthma when their child was asymptomatic. Four parents wrote about how reassuring they found a 